\title{
THE EFFECT OF LOCAL ANTIBIOTIC ON NASAL CARRIAGE OF STAPHYLOCOCCUS PYOGENES
}

\author{
By J. C. GOULD \\ Department of Bacteriology, University of Edinburgh
}

\section{INTRODUCTION}

Large numbers of healthy persons are known to be nasal carriers of Staphylococcus pyogenes and are probably the natural reservoir of pathogenic staphylococci in man. Staphylococcal lesions have always been a considerable cause of morbidity in general practice, and since most cases of staphylococcal infection are also carriers, it is probable that infection is frequently autogenous (Gould \& Cruickshank, unpublished). Most of these infections are amenable to treatment with antibiotics, but their incidence has not been reduced by the use of these agents. On the other hand, the frequency of staphylococcal infection in surgical and maternity hospitals appears to be increasing, and since many of these infections are due to antibioticresistant strains their treatment is often difficult. Means of preventing staphylococcal infection are thus important and have received most attention in hospitals where spread is believed to be due largely to cross-infection from case to case or from carrier to case. However, the reduction of hospital infection with Staph. pyogenes by barrier nursing, oiling of blankets, laying of dust, air-conditioning of theatres and wards, and strict attention to aseptic technique, have been at best only partly successful.

Since the ultimate source of infection in both hospital and non-hospital cases must be the nares of carriers it is logical to attempt prevention by reducing the infectivity of the carriers, and this may be achieved by suppressing their staphylococci. The local application of antibacterial agents may temporarily remove the organisms from the surface of the skin of the nares, but, as it is probable that the sweat and sebaceous glands are also colonized, total eradication may not be so easy to accomplish. Some experiments to control nasal carriage of staphylococci have been reported by Delafield, Straker \& Topley (1941), Hobbs, Carruthers \& Gough (1947) and Moss, Squire \& Topley (1948). They found that penicillin-sensitive Staph. pyogenes could be cleared from the nose, or reduced in numbers with locally applied penicillin but that re-infection with different strains sometimes took place.

It may be argued that topical administration of antibiotic in this way is undesirable since it has been shown that the use of penicillin is associated with an increase in the number of penicillin-resistant carrier strains (Gould \& McKillop, 1954), and the occurrence of antibiotic-resistant staphylococci in hospitals has often been correlated with the amount of corresponding antibiotic used in therapy.

This investigation was designed to find out for how long nasal carriage of Staph. pyogenes can be suppressed by the local use of antibiotics, and to assess the likelihood of development, of antibiotic resistant strains during treatment. 


\section{MATERIALS AND METHODS}

Staphylococcal carriers. Persistant nasal carriers among the non-hospital population who had been observed for at least 3 months were chosen; as far as could be estimated they were carriers of only one type of staphylococcus. Antibiotic was given in the form of a lanoline-water cream for topical application. One part of lanoline wax was thoroughly beaten up with two parts of water, and antibiotic solution of the required concentration added. Multiple samples of each batch of cream were assayed to confirm the uniform dispersion and final concentration of the antibiotic. This cream was assayed by the method of Howard (1945) and found to release antibiotic readily to an aqueous environment.

The antibiotic cream was applied several times each day to the skin of the nostrils and rubbed in with the tip of the finger. On the average $25 \mathrm{mg}$. of cream was applied to the nostril on each occasion. The number of carriers treated was equalled by those not receiving cream. A few were given cream containing no antibiotic.

Examination of the strains of Staphylococcus pyogenes. Nasal swabs from each carrier were examined weekly or more frequently by culture on milk-agar. Colonies of staphylococci were examined for morphology and pigment, and subcultures were made in broth to estimate coagulase production, antibiotic sensitivity, penicillinase production and bacteriophage type. Each carrier was examined over at least 20 weeks and representative cultures were periodically kept for comparison with organisms isolated at later stages of the experiment.

\section{RESULTS}

\section{Estimation of the minimum effective concentration of antibiotic}

Preliminary experiments with penicillin cream showed that a concentration below 1000 units per gram was usually ineffective in producing nose swab cultures free of Staph. pyogenes, even during the period of application of the cream. Concentrations up to 10,000 units per gram were increasingly effective. Presumably these higher concentrations are required to overcome loss by absorption, and dispersal, and to leave sufficient antibiotic to kill the organisms on the surface and to penetrate into the glands. Cream containing 100,000 units per gram was not appreciably more effective in clearing staphylococci from the surface of the nares. Similarly, $0 \cdot 1 \%$ concentrations of streptomycin, chloramphenicol, chlortetracyline (aureomycin) and oxytetracycline (terramycin) were much less effective than $1 \%$ concentrations. Since it has been reported that the development of resistance is more likely after exposure to a high concentration of antibiotic when sterilization is not complete (Gould, Bowie \& Cameron, 1953) and since resistance is more likely to appear after prolonged treatment with antibiotic, it was decided to make most of the tests with cream containing $1 \%$ antibiotic, and to limit the period of application to 14 days. 


\section{Effect of antibiotic cream on antibiotic-sensitive staphylococci in the nares}

In all carriers there was a marked fall in the numbers of colonies of staphylococci isolated from nasal swab cultures taken during the time antibiotic was being applied.

One week after the start of treatment no colonies of Staph. pyogenes were isolated from 96 out of 124 carriers. Oxytetracycline was the most effective; Staph. pyogenes was absent from nose swab cultures taken from all carriers who had had 1 week's treatment with this antibiotic. In the same way chlortetracycline cleared $86 \%$; penicillin $77 \%$; streptomycin $71 \%$ and chloramphenicol $67 \%$.

Sixty-nine per cent of all the treated carriers gave nose swabs culturally negative for Staph. pyogenes for 2 weeks or more after withdrawal of the antibiotic. Forty-nine per cent remained negative for at least 1 month and $26 \%$ for 20 weeks (Table 1). These figures were approximately the same for all the antibiotics used. During the same period the rate of spontaneous change from the carrier to the non-carrier state was $1 \%$ in the control group of carriers who received no antibiotic.

Table 1. Isolation of Staphylococcus pyogenes from nasal swab cultures following local application of various antibiotics. Occurrence of replacement strains

\begin{tabular}{|c|c|c|c|c|c|c|c|c|c|}
\hline \multirow{3}{*}{$\begin{array}{l}1 \% \text { antibiotic } \\
\text { cream } \\
\text { administered } \\
7-14 \text { days }\end{array}$} & \multirow{3}{*}{$\begin{array}{l}\text { No. } \\
\text { receiving } \\
\text { antibiotic }\end{array}$} & \multicolumn{5}{|c|}{$\begin{array}{l}\text { No. in whom nasal swab } \\
\text { negative for Staph. pyogenes }\end{array}$} & \multicolumn{3}{|c|}{ No. in whom } \\
\hline & & $\begin{array}{l}\text { After } \\
1 \text { week's }\end{array}$ & $\overbrace{}^{2}$ & $\begin{array}{l}\text { Week } \\
\text { withd } \\
\text { anti }\end{array}$ & $\begin{array}{l}\text { zs af } \\
\text { raws } \\
\text { ibiot }\end{array}$ & ter & $\begin{array}{c}\text { Original } \\
\text { strain } \\
\text { persisted } \\
\text { or returned }\end{array}$ & $\begin{array}{l}\text { Replace- } \\
\text { ment }\end{array}$ & \\
\hline & & $\begin{array}{l}\text { tion of } \\
\text { antibiotic }\end{array}$ & $<1$ & $1>2$ & $>4$ & $\begin{array}{l}20 \text { or } \\
\text { more }\end{array}$ & $\begin{array}{l}\text { porary } \\
\text { absence }\end{array}$ & $\begin{array}{c}\text { temporarily } \\
\text { present }\end{array}$ & $\begin{array}{c}\text { ment strain } \\
\text { persisted }\end{array}$ \\
\hline Penicillin & 44 & 34 & 11 & 33 & 20 & 11 & 32 & 16 & 1 \\
\hline Streptomycin & 21 & 15 & 6 & 15 & 12 & 6 & 15 & 5 & 0 \\
\hline Chloramphenicol & 18 & 12 & 9 & 9 & 9 & 6 & 12 & 3 & 0 \\
\hline $\begin{array}{l}\text { Chlortetracycline } \\
\text { (aureomycin) }\end{array}$ & 21 & 18 & 6 & 15 & 12 & 6 & 15 & 1 & 0 \\
\hline $\begin{array}{l}\text { Oxytetracycline } \\
\text { (terramycin) }\end{array}$ & 20 & 20 & 7 & 13 & 8 & 4 & 16 & 3 & 0 \\
\hline Total & 124 & 99 & 39 & 85 & 61 & 33 & 90 & 28 & 1 \\
\hline
\end{tabular}

\section{Observed changes in antibiotic sensitivity}

From twenty-four carriers receiving antibiotic cream, antibiotic-resistant strains of Staph. pyogenes were isolated, and these strains were all either of bacteriophage type different from that of the corresponding original carrier strains, or did not react with phage filtrates. Two-thirds of the typable strains belonged to phage group III (Table 2). Replacement with these resistant strains of Staph. pyogenes was a temporary episode, except in one carrier receiving penicillin cream in whom the penicillin-resistant strain isolated after withdrawal of the antibiotic persisted during the whole period of observation. In a further four carriers receiving 
penicillin cream there was replacement, for a limited period, with a penicillinsensitive strain of different phage type. In the remaining carriers a strain of the same antibiotic sensitivity and phage type as the original returned after a few weeks, and the resistant strain disappeared.

Table 2. Bacteriophage type and antibiotic sensitivity of original and replacement strains

\begin{tabular}{|c|c|c|c|c|}
\hline \multirow[b]{2}{*}{$\begin{array}{l}\text { Carrier } \\
\text { number }\end{array}$} & \multicolumn{2}{|c|}{ Phage type of } & \multicolumn{2}{|c|}{ Antibiotic sensitivity } \\
\hline & Original strain & $\begin{array}{l}\text { Replacement } \\
\text { strain }\end{array}$ & $\begin{array}{l}\text { Original } \\
\text { strain }\end{array}$ & $\begin{array}{l}\text { Replacement } \\
\text { strain }\end{array}$ \\
\hline \multicolumn{5}{|c|}{ Penicillin (units/ml.) } \\
\hline 6 & $47 \mathrm{~A} / 47 \mathrm{C}$ & 52 & 0.03 & 3 \\
\hline 11 & $3 \mathrm{~A} / \mathbf{3} \mathrm{B}$ & $76 / 77$ & 0.03 & 1.5 \\
\hline 16 & $3 \mathrm{~A}$ & $47 \mathrm{~A} / 54$ & 0.04 & 3 \\
\hline 25 & $47 \mathrm{C}$ & $47 \mathrm{C} / 45 / 75$ & 0.06 & $1 \cdot 2$ \\
\hline 39 & $\mathbf{3 A}$ & $29 / 42 \mathrm{E}$ & 0.03 & 0.03 \\
\hline $44 \mathrm{~A}$ & $52 / 52 \mathrm{~A}$ & $52 \mathrm{~A}$ & 0.03 & 2 \\
\hline 45 & $47+$ & $47 \mathrm{~A}$ & 3 & 0.03 \\
\hline 47 & $47 \mathrm{~A}$ & 51 & 0.06 & $0 \cdot 03$ \\
\hline 48 & 51 & $3 \mathrm{~B}$ & 0.03 & $0 \cdot 036$ \\
\hline 66 & $3 \mathrm{~A} / 51$ & $7 / 47 / 54$ & 0.03 & 3 \\
\hline 74 & $3 \mathrm{~A} / 3 \mathrm{C}$ & $7 / 47 / 54$ & 0.06 & 3 \\
\hline 119 & 52 & $7 / 47 / 54$ & 0.03 & $\mathbf{l}$ \\
\hline 122 & $6 / 47 \mathrm{~A} / 54$ & $\mathrm{NT}^{*}$ & 0.03 & $2 \cdot 25$ \\
\hline 126 & $3 \mathrm{C} / 51$ & $6 / 47 / 53$ & 0.03 & $2 \cdot 25$ \\
\hline 157 & $6 / 7 / 53$ & NT & 0.03 & 2 \\
\hline 171 & $52 / 52 \mathrm{~A}$ & $7 / 47 / 53$ & 0.03 & 3 \\
\hline 523 & $44 \mathrm{~A} / 52$ & $\mathrm{NT}$ & $0 \cdot 03$ & $0 \cdot 03$ \\
\hline \multicolumn{5}{|c|}{ Streptomycin $(\mu \mathrm{g} . / \mathrm{ml})}$. \\
\hline 411 & $3 \mathrm{~B} / 55$ & $6 / 7 / 47 / 53$ & 0.5 & 20 \\
\hline 415 & NT & $76 / 77$ & $1 \cdot 0$ & 30 \\
\hline 420 & 54 & NT & $1 \cdot 0$ & 25 \\
\hline 422 & $3 \mathrm{~B} / 3 \mathrm{C} / 5 \mathrm{I}$ & NT & $1 \cdot 0$ & 25 \\
\hline 440 & 52 & NT & 0.5 & 15 \\
\hline \multicolumn{5}{|c|}{ Chloromycetin ( $\mu \mathrm{g} . / \mathrm{ml})}$. \\
\hline 521 & NT & $52 \mathrm{~A}$ & 1.5 & 15 \\
\hline 529 & $52 \mathrm{~A}$ & NT & $3 \cdot 0$ & 20 \\
\hline 530 & $6 / 7 / 53$ & $52 \mathrm{~A}$ & $2 \cdot 5$ & 20 \\
\hline \multicolumn{5}{|c|}{ Terramycin ( $\mu \mathrm{g} . / \mathrm{ml})}$. \\
\hline 5 & $42 \mathrm{E} / 47 / 47 \mathrm{C}$ & $47 / 54$ & $0 \cdot 25$ & 6 \\
\hline 11 & $52 \mathrm{~A}$ & NT & 0.5 & 25 \\
\hline 43 & $3 \mathrm{~A}$ & $47 / 47 \mathrm{~A}$ & $0 \cdot 2$ & 250 \\
\hline \multicolumn{5}{|c|}{ Aureomycin $(\mu \mathrm{g} . / \mathrm{ml})}$. \\
\hline 602 & $3 \mathrm{C} / 51$ & $\mathrm{NT}$ & $0 \cdot 25$ & 250 \\
\hline & & not typable. & & \\
\hline
\end{tabular}

Suppression of penicillin-resistant carrier strains of Staphylococcus pyogenes

Eight carriers of penicillinase-producing strains of Staph. pyogenes were given penicillin cream containing 100,000 units per gram. In four of them the organism disappeared from nose swab cultures for periods of $2-6$ weeks; in a fifth there was 
apparent replacement with a strain of different phage type which was penicillinsensitive (Table 2, carrier 45) and in the remaining three the original carrier strain persisted.

Two carriers of penicillin-resistant strains were treated with chlortetracycline cream for 3 days, followed by penicillin cream for 10 days. In both cases the organism was more sensitive to penicillin after exhibition of the aureomycin, but was not suppressed by either antibiotic, although the number of colonies isolated on culture was greatly reduced.

\section{Administration of antibiotic-free cream}

Twelve carriers and twelve non-carriers were given antibiotic-free cream for 2 weeks. This had no effect, qualitatively, or quantitatively, on the flora of the anterior nares of any of these individuals.

\section{DISCUSSION}

These experiments have shown that the topical application of $1 \%$ antibiotic cream was effective in suppressing Staph. pyogenes in the human nose for an appreciably longer time than the cream was applied. It is unlikely that the organism ceased to colonize the skin glands of the nares but rather that it was not present on the surface at the time of swabbing. However, even if this was so it is still reasonable to suppose that the staphylococcus was not being passed to other sites on the body, nor disseminated into the air and dust, and therefore that the infectivity of these carriers was reduced.

Thus most of the carriers treated in this series remained in a state of reduced infectivity for about a month after the antibiotic cream ceased to be applied. Recolonization of the surface of the skin of the nares may be followed by further limited courses of similar treatment suitably controlled by bacteriological examinations. In this way staphylococci in the nose may be more or less continuously suppressed for a prolonged period. The justification for this procedure must be a proved reduction in the incidence of staphylococcal infection and this is being investigated both in hospital (Gould \& Allan, 1954) and in recurrent staphylococcal infection among non-hospital patients.

The antibiotics tested were more or less equally effective in suppressing antibiotic-susceptible strains of Staph. pyogenes in the nose. No carriers of antibioticresistant strains, other than a limited number of penicillin-resistant strain carriers, were available for study. A higher concentration of penicillin was fairly successful in suppressing these penicillinase producers and there was evidence that chlortetracycline might be useful in such cases. A likely consequence of this method of treating carriers is that they will become reservoirs of antibiotic-resistant strains. In this particular experiment the end-result was not unfavourable in this respect, since only one carrier, treated with penicillin, was observed to continue carrying a penicillin-resistant strain for more than a few weeks. However, about $20 \%$ of the treated carriers were temporarily colonized with antibiotic-resistant strains, an indication that there is some danger that they may spread resistant organisms. 
The source of these resistant strains is doubtful. They may have arisen by mutation or adaptation of the parent antibiotic-sensitive strains; but as all of the antibioticresistant variants were of different phage type from the sensitive strains in the carriers in whom they appeared this explanation is unlikely, unless the change in antibiotic sensitivity is associated with a change in phage type (Gould, 1955).

A second possibility is that two strains of staphylococci were present in the nares of these carriers, one of greater antibiotic resistance than the other and so favoured by the presence of antibiotic. The carriers in this series were chosen because they appeared to harbour only one strain of well-defined phage type, but the possibility of a second strain being present in small numbers cannot be ruled out.

Thirdly, the resistant strains could have been acquired from the external environment. An antibiotic-resistant staphylococcus deposited on the skin of the nares by inhalation would find conditions favourable for growth, and would be isolated while the sensitive strain was suppressed by antibiotic. Withdrawal of the antibiotic would once again favour the original sensitive strain allowing it to overgrow the resistant strain. Re-establishment of the sensitive strain would be more likely to occur in carriers among the general community who are not continuously exposed to reinfection with antibiotic-resistant organisms, nor to repeated contact with antibiotic, as they would be in hospital environments.

\section{SUMMARY}

Lanoline-water cream containing $1 \%$ of antibiotic was applied for 7-14 days to the anterior nares of 124 carriers of antibiotic sensitive staphylococci. Nose swab cultures, examined during the administration of the cream, were negative for Staph. pyogenes in all carriers who received oxytetracycline, and in $80,75,70$ and $67 \%$ of those who received penicillin, chlortetracycline, streptomycin and chloramphenicol respectively.

Seventy per cent of carriers gave nose-swab cultures negative for at least 2 weeks, $50 \%$ for at least 4 weeks and $25 \%$ for at least 20 weeks after the cessation of treatment. Over the same period only $1 \%$ of a control group ceased to be carriers.

The nares of $20 \%$ of carriers receiving antibiotic were temporarily colonized with antibiotic-resistant strains, but in only one case $(0.8 \%)$ did the resistant organism persist throughout the period of examination.

The use of this method of controlllng staphylococcal carriage in preventing staphylococcal infection is discussed.

I wish to thank Prof. T. J. Mackie for his advice.

\section{REFERENCES}

Delafield, M. E., Straker, E. \& Topley, W. W. C. (1941). Antiseptic snuffs. Brit. med. $J$. i, 145 .

GouLd, J. C. (1955). The origin of antibiotic-resistant staphylococci. Nature, Lond. (in the Press).

Gould, J. C. \& Allax, W. S. A. (1954). Staphylococeus pyogenes eross-infection. Lancet, ii, 988. 
Gould, J. C., Bowie, J. H. \& Cameron, J. D. S. (1953). Dosage of antibiotics. Lancet, i, 361. Gould, J. C. \& McKillop, E. J. (1954). Staphylococcus pyogenes; the antibiotic sensitivity of strains isolated from human carriers. J. Hyg., Camb., 52, 486.

Hobrs, B. C., Carruthers, H. L., Gough, J. (1947). Sycosis Barbae; serological types of Staphylococcus pyogenes in nose and skin and results of penicillin treatment. Lancet, ii, 572.

HowARD, R. W. (1945). An evaluation of sulphonamide ointment bases. New Engl. J. Med. 232, 698.

Moss, B., SQurre, J. R. \& Toptey, E. (1948). Nose and skin carriage of Staphylococcus aureus in patients receiving penicillin. Lancet, $\mathrm{i}, 320$.

(MS. received for publication $17 . \mathrm{v} .55$ ) 
